\title{
PRIMEIRO REGISTRO DO GÊNERO BIANCOLINA (AMPHIPODA, AMPITHOIDAE) PARA O BRASIL, COM DESCRIÇÃO DE UMA ESPÉCIE NOVA
}

\author{
Andrade, R.M. ${ }^{1{ }^{*}}$ \& Souza-Filho, J.F. ${ }^{1}$ \\ ${ }^{1}$ Universidade Federal de Pernambuco (UFPE), Campus Recife, Museu de Oceanografia. \\ *Autor correspondente: renan_andrade16@hotmail.com, jesser_fidelis@yahoo.com.br
}

O gênero Biancolina é um dos gêneros mais raros de Amphipoda. Constituem um grupo herbívoro especialista, preferindo as algas do gênero Sargassum (uma exceção dentro da família), habitam canais construídos nos tecidos algais. Atualmente compreendem sete espécies, das quais apenas duas ocorrem no Atlântico (Mar do Sargasso e Cuba). Devido a presença de vários caracteres morfológicos convergentes ao estilo de vida críptico, o histórico taxonômico do grupo é relativamente confuso, com alocação em diferentes famílias ao longo do tempo. Recentemente, o gênero que constituía uma família monotípica (Biancolinidade) foi transferido para a família Ampihtoidae, com base em uma análise de filogenia molecular. O objetivo do trabalho foi descrever uma nova espécie do gênero Biancolina, que representa o primeiro registro do gênero para o Brasil. O material estudado foi coletado através de duas amostragens durante o período chuvoso de 2018 (maio e julho) na Baia de Suape, Pernambuco. Após a coleta, as frondes foram embebidas com uma pequena dosagem da solução de formol à $4 \%$ para que a para facilitar o desprendimento da fauna associada. Em seguida, o material triado foi transferido para álcool 75\% e tombado na Coleção de Crustáceos do Museu de Oceanografia Prof. Petrônio Alves Coelho. Foram encontrados 51 espécimes de Biancolina no total. O holótipo (fêmea) e parátipos (macho e fêmea) foram ilustrados com auxílio de câmara clara acoplada a microscópio ótico e os desenhos vetorizados no programa gráfico Corel Draw X7. Biancolina sp. nov. é próxima a B. japonica Ishimaru, 1996, conhecida para o Mar do Japão e Austrália, por apresentar os seguintes caracteres: antena 1 duas vezes mais longas que a antena 2, lacinia mobilis nas duas mandíbulas, artículo 4 do palpo do maxilípodo bulboso, ramo externo dos urópodos pelo menos metade do comprimento do ramos interno, coxas 5 e 6 com lobo anteroventral bem desenvolvido e telso apenas com um pequeno entalhe distal. Entretanto, Biancolina sp. nov. pode ser diferenciada de $B$. japonica (caracteres diferencias entre parênteses): coxa 6 com lobo anteroventral tão desenvolvido quanto o lobo posteroventral (vs. lobo anteroventral mais desenvolvido que o lobo posteroventral), pedúnculo do urópodo 1 pouco cerdoso (vs. muito cerdoso) e palma dos pereópodos 5 a 7 sem cerda robusta ( $v s$. com cerda robusta). O presente trabalho eleva para quatro o número de gêneros da família Ampithoidae registrados para o Brasil.

Keywords: taxonomia, Ampithoidae, Senticaudata, fauna associada, Pernambuco. 